\title{
Essays
}

\section{Academic research: the difficulty of being simple and beautiful}

\author{
Quan Hoang Vuong \\ FPT University, FSB School of Business; qvuong@ulb.ac.be \\ Nancy K. Napier \\ Boise State University; nnapier@boisestate.edu
}

DOI: 10.20316/ESE.2017.43.002

\begin{abstract}
In this essay, we share our experience and learning about the value of, and the difficulty associated with, conducting and presenting scientific studies in ways that are both simple (understandable) and beautiful (appealing to the reader). We describe some "aha moments" of insight that led to changes in the way we approach and present research, some of the actions we took, and lessons we learned.
\end{abstract}

\section{Keywords}

Academic writing, simplicity, tenacity, scientific publication

\section{Introduction}

During a recent project to understand entrepreneurs attitudes toward risk-taking and creativity, we learned from our participants and took our own risks in the way we presented the research for public use. In this essay, we describe the process of preparing the results, how we decided to change the way we present research findings, and what we learned that may be useful for others.

\section{The background}

The project on entrepreneurs included a data set containing over 3000 observations, each with a dozen attributes characterising a data point ${ }^{1}$. We followed the usual practice of collecting data from interviews with participants, using the survey data to build tables of structured data and create frequency distributions and analytical frameworks. We ran models, considered parsimonious functional forms, and computed quantities and full distributions of values. We tested and confirmed theoretical relations based on empirical data, and then tried to uncover insights and "plausible reasoning". The process was one of collecting, arranging, sorting out, transforming and fitting the numbers, computing new numbers and seeking to understand the meanings of numbers. Interesting work for researchers but who else would care about these thousands of numbers and hours of work?

\section{Aha moment \# 1: Making research useful in a wider world}

As we analysed and organised, we came to realised that for the findings to matter the results needed to be understandable to an audience beyond just other researchers. While the details made sense to us, as the researchers living with the numbers, we had to find a way to present critical information in a way that sparked curiosity, could be memorable, and would raise questions for those who wanted to learn more. To get there, we had to do things differently.

First, we returned to the mess of data and asked a different question: "How can we make the data more useful, feasible to study, and interesting for the research questions at hand?" The treatment involved transformation of data (continuous or discrete/categorical), and determining the technical specification with the least number of variables for fitting. We also considered how to structure the data subsets regarding specific questions. This seemingly never-ending task finally led to structures and associated meanings that made more sense.

Second, instead of asking whether these computations were enough for substantial results, we asked ourselves: "What else could we do to learn more?" This reminded us of the quote from economist Ronald Coarse: "If you torture the data long enough, Nature will confess"3. Somehow this suddenly became useful. So in computation after computation, we asked: "Is this result the 'best-available' or 'good' or 'just good-looking?"'

Third, and most importantly, we challenged ourselves to see if we could present and explain the findings and results in a way, as suggested by Albert Einstein, that a fifth grader could understand and appreciate.

\section{Aha moment \#2: Thinking like an entrepreneur}

In this new approach, we were like the "entrepreneurs" in our study: risk-taking, hard-working, and creative. In the end, we were forced to "innovate" to seek a novel way of understanding. We went back to the mess of data, computing and re-doing, keeping an eye on the risk of misspecification and spurious correlations. It helped to recall that Michael Faraday performed 16,041 experiments and Thomas Edison tried 1000 times with his light bulb invention.

Eventually, as time and resources are always limited, we had to focus our efforts on a few instead of many things. In the end, we made numbers fade into the background and concentrated on drawing graphs that would better reveal our data. In fact, sometimes "few choices" are better than too many, and we decided to pull the most interesting numbers and graphs out of the data rather than wander and include more. The graphs reminded us of Claude Monet's many paintings of the water lily ponds at Giverny. Monet brought light to colours and, we asked, do researchers not try to do the same by shedding light on some conjectures?

Sometimes, it takes many attempts and many angles to do this, as Monet did repeatedly, and as we tried as well. 
The process took three times as long as our "standard" analysis for an observational study. We eventually boiled down the key information to two graphs, which became the core of the paper, with the rest of the numbers and text as support. The editor accepted the paper with minor revisions.

\section{Aha moment \#3: Identifying a key lesson}

Through this trial and error process, we discovered a tactic that we now use regularly: make an explanation simple and beautiful. Doing so demands time and effort. Even though we understood intellectually how important simplicity and beauty are in communication, we still struggled with the execution. Indeed, many journal editors and communication experts over the years have encouraged researchers to use more accessible means to present findings. But it continues to be difficult even after many attempts. So we offer another way of understanding what has been simple and beautiful and useful for us. It takes the form of a "mantra":

We seek to achieve the simple and beautiful ...

1. Present complex information so readers can grasp it relatively easily,

2. ... in a format that sparks curiosity and encourages them to connect some dots,

3. ... that can be more readily remembered,

4. ... and that makes readers want to know "a little more".

The more we have worked with this idea during our research endeavours, the better we have been able to understand the importance of bringing research findings to the broader world. Ideas that are not usually seen as "beautiful" by lay people can be viewed differently if we follow this thinking.

This process also helped us realise again the value of using visuals to convey ideas, not only graphs but also metaphors and visual images. Many famous researchers have used the technique: think of the double helix, the solar system, the "black swan" or the "invisible gorilla". We have begun to use more visuals ourselves, including recently the notion of a "mindsponge" to represent the process of squeezing out ideas and bringing new ones to the surface ${ }^{5}$. Visualisations help us understand and remember. And if we are fortunate, the simple and beautiful may help research knowledge spread to lay people, policy makers, and business managers.

Editors of scientific publications are in the best position to understand both the value and difficulty of simple writing; and researchers as submitting authors are well advised on this matter ${ }^{6,7}$. But there is more editors could do to help promote the concept, such as: i) publishing editorials, concise and simple, that attract submitting authors' attention about this principle; ii) stating in editorial opinions a preference for simple and clear presentation with the help of graphs, visuals, etc; iii) at conferences' "meet the editors" sessions, conveying and discussing the idea with prospective authors, with emphasis on the emerging trend of making science communication of real value for both the scholarly community and the public. Sources such as the EASE Guidelines should be better used for promoting the value of simplicity and beauty in the scientific enterprise ${ }^{8}$. Researchers would then be better off, benefiting from shared experiences and skills from well-versed scholars in their field ${ }^{9,10,11}$.

We continue to build on this experience and are finding that it is indeed useful beyond publishing in research journals. In fact, as they seek to promote evidence-based policy making, including on matters dealing with science policies, policy makers in Vietnam have become more interested in our research. They have reached out for advice, partly because of some of our recent research. When we ask what intrigues them about it, they say "the research insights are easy to understand (simple) and the graphs are appealing (beautiful)!"

\section{References}

1 Vuong QH. Survey data on entrepreneurs' subjective plan and perceptions of the likelihood of success. Data in Brief 2016;6:858-864. doi:10.1016/j.dib.2016.01.034.

2 Pólya G. Mathematics and plausible reasoning: induction and analogy in mathematics. Princeton, NJ: Princeton University Press, 1990.

3 Kennedy PE. Sinning in the basement: what are the rules? The ten commandments of applied econometrics. Journal of Economic Surveys 2002;16(4):569-589.

4 Vuong QH, Napier NK, Do TH, Vuong TT. Creativity and entrepreneurial efforts in an emerging economy. Business Creativity and the Creative Economy 2016;2(1):39-50.

5 Vuong QH, Napier NK. Acculturation and global mindsponge: an emerging market perspective. International Journal of Intercultural Relations 2015;49:354-367.

6 Daft RL. Why I recommended that your manuscript be rejected and what you can do about it. In: Cummings LL, Frost PJ (eds). Publishing in the organizational sciences. Thousand Oaks, CA: Sage Publications, 1995:164-182

7 Lange P. How to write a scientific paper for peer-reviewed journals. The European Association of Science Editors (EASE). http://www.ease.org. $\mathrm{uk} /$ publications/ease-toolkit-authors/how-to-write-a-scientific-paperfor-peer-reviewed-journals/ [accessed 2017 March 12]

8 EASE. Guidelines for Authors and Translators of Scientific Articles to be Published in English. Available from: http://www.ease.org.uk/ publications/author-guidelines-authors-and-translators/ [accessed 2017 March 12]

9 Davis MS. That's interesting! Towards a phenomenology of sociology and a sociology of phenomenology. Philosophy of the Social Sciences 1971;1:09-344.

10 Rynes SI, Hillman A, Ireland RD, Kirkman B, Law K, Miller CC, Rajagopalan N, Shapiro D. Everything you've always wanted to know about AMJ (but may have been afraid to ask). Academy of Management Journal 2005;48(5):732-737.

11 Olson R. Houston, we have a narrative. Chicago: The University of Chicago Press, 2015. 